First publ. in: Aquatic Botany 79 (2004), pp. 277-294

\title{
Amino acids as indicators of physiological stress in common reed Phragmites australis affected by an extreme flood
}

\author{
Heike Koppitz ${ }^{\mathrm{a}, *}$, Marion Dewender ${ }^{\mathrm{a}}$, \\ Wolfgang Ostendorp ${ }^{\mathrm{b}}$, Klaus Schmieder ${ }^{\mathrm{c}}$ \\ a Department of Biology/Ecology, Humboldt-University Berlin, Unter den Linden 6, \\ D-10099 Berlin, Germany \\ b Limnologisches Institut, Universität Konstanz, D-78457 Konstanz, Germany \\ c Institute of Landscape and Plant Ecology (320), University of Hohenheim. \\ D-70593 Stuttgart, Germany
}

\begin{abstract}
The effects of extreme flooding at Lake Constance on the content and composition of amino acids in Phragmites australis were studied at nine reed stands with different degrees of damage. Following the flood damage, we discovered a complex die-back syndrome which is characterised by a decrease in total culm density from 32 to 4 culms $\mathrm{m}^{-2}$, an increase in percentage of secondary shoots by $70 \%$ and decline in mean culm biomass by $27 \mathrm{gdry}$ wt. Furthermore, a reduction of total carbohydrates by $60 \%$, starch by $56-70 \%$ and soluble sugars by $49-59 \%$ in the vertical and horizontal storage rhizomes was found, together with changes in the composition of amino acids in the basal culm internodes. Within primary shoots from extremely damaged reed stands we found a significant increase in the total content of amino acids ( 150 versus $40 \mu \mathrm{mol}$ amino acid $\mathrm{g}^{-1} \mathrm{dry}$ wt. in undamaged stands). Asparagine (Asn) contributed one of the largest fractions to total amino acids, on average about $25 \%$ in undamaged reed stands. In contrast, the main amino acid of primary shoots from extremely damaged reeds was not Asn (15\%) but $\gamma$-aminobutyric acid (Gaba). Its share was $36 \%$ in primary shoots and $48 \%$ in insect-infested primary shoots, respectively. This is the highest Gaba content reported in $P$. australis. The significant increase in the share of $\gamma$-aminobutyric acid in shoots from extremely damaged reed stands was accompanied by an increase in alanine. These
\end{abstract}

* Corresponding author. Tel.: +49 3020936527 ; fax: +49 3020936530.

E-mail addresses: heike.koppitz@rz.hu-berlin.de (H. Koppitz), wolfgang.ostendorp@uni-konstanz.de (W. Ostendorp), schmied@uni-hohenheim.de (K. Schmieder). 
changes in the composition of amino acids are discussed with respect to the significance of certain amino acids acting as stress indicators, such as oxygen deprivation, causing a hypoxic metabolic state in $P$. australis stands.

Keywords: Asparagine; Dissolved amino acids; $\gamma$-Aminobutyric acid; Gaba accumulation; Hypoxia; Lake Constance; Water level fluctuations

\section{Introduction}

The common reed Phragmites australis (Cav.) Trin. ex Steud. (Poaceae) grows in a wide range of habitats, including the littoral zone of most European lakes and rivers. Although very commonly found in these areas, a significant decline in reed belt area has been observed at approximately 60 lakes in Europe. A lot of ecological factors have been made responsible for the die-back of reed, and many studies have tried to discover ecophysiological mechanisms and tolerance limits of $P$. australis (see Ostendorp (1989), Van der Putten (1997) and Brix (1999) for a review). During the late 1960s and 1970s a rapid decline of aquatic reed beds was observed in Lake Constance due to an extreme flood in 1965 (Ostendorp, 1990). Again, in 1999 extreme flooding occurred. Water levels rose very early in the season to the third highest on record since daily water level records began in 1817. The maximum water level was reached already in mid May and lasted exceptionally long (approximately 2 months). During the vegetation period of 1999 , the reed belts showed a severe loss in vitality so that permanent damage could be expected. Therefore, a monitoring project was established, which focused on the documentation of future developments, the identification of co-factors, and was designed to find out significant stress factors that might impede the recovery of the reeds (Schmieder et al., 2002; Ostendorp et al., 2003).

Flooding, insect or fungal infestation, mechanical damage and loss of culms can reduce the convective gas flow to the basal parts of the reed plants (Armstrong et al., 1996). This leads to an oxygen deficiency in the roots and the rhizomes, changing the metabolic status of the whole plant. Fermentation processes may become active producing ethanol, lactate and some other compounds (Brändle and Crawford, 1987). Presumably, the shift in central metabolic pools is reflected by changed amino acid patterns in the rhizomes and in the basal culm internodes of $P$. australis (Kohl and Henning, 1987; Haldemann and Brändle, 1988; Kohl et al., 1998). This amino acid pattern could possibly be used as an indicator of the anaerobic status of root metabolism.

In this paper we link the visible impact of extreme flooding on the stand structure and the aboveground biomass of aquatic reed belts in Lake Constance with (1) the content of dissolved amino acids in the basal shoot internodes of differently damaged reed stands, (2) the pattern of amino acid composition, and (3) the carbohydrate content in the rhizomes. We also discuss the significance of certain amino acids as indicators of the hypoxic status of metabolism in damaged $P$. australis stands. 


\section{Materials and methods}

\subsection{Site description}

By area and volume Lake Constance is the second largest prealpine European lake. The lake is divided into a deep Upper Lake ("Obersee") and a Lower Lake ("Untersee") with gently sloping shelves and broad reed belts. Lake Constance is characterised by almost natural annual water level fluctuations, since its outflow has not been modified. More than $90 \%$ of the water inflow comes from the alpine catchment. The minimum water level usually occurs in January or February due to immobilisation of precipitation as snow and ice in the alpine catchment and is highest in June/July due to thaw. The amplitude of the yearly mean water level course is $1.43 \mathrm{~m}$ (Luft and van den Eertwegh, 1991). In 1999 an extreme high water level event occurred (Schmieder et al., 2002; Ostendorp et al., 2003). The results presented in this paper refer to Lake Constance-Untersee only.

\subsection{Field sampling}

Along with the visual evaluation of colour infra red (CIR) aerial photos, five degrees of damage were defined. These ranged from G1 (not damaged) over G3 (significantly damaged) to G5 (extremely damaged) according to the percentage of red coloured area (i.e. intact Phragmites stands) and the degree of disintegration of the reed bed (for details, see Schmieder et al. (2002)). Nine stands at the lakeside reed border (three in the G1, G3 and G5 group, respectively) were selected for sampling. Stand structure measurements were performed at the time of peak standing crop in late August 2000, culm basal internodes were sampled during the first week of September, and the rhizomes were dug out in early March 2001, about 6 weeks before the beginning of growth of the new shoot generation. Along with the rhizome sampling, sediment cores $(0-20 \mathrm{~cm}$ depth) were taken using hand-driven Perspex tube of $4 \mathrm{~cm}$ diameter.

According to the stand structure and the basal internodes, three shoot classes were distinguished: (i) primary (flowering) shoots (PSH), (ii) secondary (replacement) shoots (SSH) and (iii) insect-infested shoots (shoots with an apical gall formed by Lipara sp., Dipt., Chloropidae) (ISH). Stand structure, culm morphology and aboveground standing crop measurements were the same as described in Schmieder et al. (2002). Sedimentological variables were measured according to Ostendorp and Blum (1998).

For amino acid analysis, five randomly selected culms in each shoot class (exception: at G5-stands not all types of shoots were abundant) were clipped at ground level. The basal internodes were detached, cleaned with deionized water, and immediately frozen in liquid nitrogen.

The rhizomes were dug out from the soil down to a depth of $0.6 \mathrm{~m}$. According to their position in the polykorm body, the rhizome pieces were grouped into vertical rhizomes of that year (RVN), older vertical rhizomes (RVA), and horizontal storage rhizomes (RHO). Approximately 10-20 internodes were searched for holes bored by larvae of the reed beetle Donacia clavipes Fabricius, Col., Chrysomelidae. Subsamples of each piece were kept at $4^{\circ} \mathrm{C}$ and processed on the same day, cleaned, lyophilized and homogenised in a centrifugal mill (particle size $<40 \mu \mathrm{m}$ ). 


\subsection{Analyses of dissolved amino acids}

After freeze-drying at $-20^{\circ} \mathrm{C}$ in a vacuum evaporator (Christ, Germany), the samples were homogenised in a swing-mill MM 2000 (Retsch, Germany) in liquid nitrogen. Approximately $70-80 \mathrm{mg}$ of powdered samples were extracted three times with $80 \%(\mathrm{v} / \mathrm{v})$ ethanol at room temperature and centrifuged $(5000 \times g)$. Norleucine as an internal standard was added to the samples during extraction and the first step of extraction included a treatment in an ultrasonic bath $\left(10 \mathrm{~min}, 4^{\circ} \mathrm{C}\right)$. An aliquot of the combined supernatants was purified by ultrafiltration through Ultrafree-MC-membranes (Millipore Corporation, USA), freeze-dried and redried in methanol/sodium acetate/triethylamine $(2: 2: 1, \mathrm{v} / \mathrm{v})$ at $4{ }^{\circ} \mathrm{C}$. The extracted samples and standard mixtures of amino acids were derivatised with phenylisothiocyanate to give phenylthiocarbamyl amino acids, using the Pico-Tag ${ }^{\circledR}$ method for free amino acids (Bidlingmeyer et al., 1984; Cohen and Strydom, 1988), and freeze-dried at $4{ }^{\circ} \mathrm{C}$. Samples were re-dissolved in phosphate buffer, and separated and detected using an HPLC system (Kontron, Germany; gradient pump system 525 , autosampler 565 , Sentry nova pak C18 precolumn, Pico-Tag ${ }^{\circledR}$ column for free amino acids (Waters Corporation USA, $3.9 \mathrm{~mm}$ $\times 300 \mathrm{~mm}$ ), UV/VIS detector 535 (at $254 \mathrm{~nm}$ )) according to the Pico-Tag ${ }^{\circledR}$ method with modifications of eluents (cf. Hagen et al., 1993; Cohen, Waters Corporation, personal communication). Different compositions of eluent ingredients were tested. The following gave the most satisfactory results in quantification of dissolved amino acids. Eluent 1: $975 \mathrm{~mL}$ of $0.07 \mathrm{~N}$ sodium acetate trihydrate, titrated to $\mathrm{pH} 6.5$ with glacial acetic acid, mixed with $25 \mathrm{~mL}$ acetonitrile, then an addition of $200 \mu \mathrm{L}$ fresh solution of $1 \mathrm{mg} \mathrm{EDTA} \mathrm{mL}^{-1}$ deionized water. Eluent 2: $600 \mathrm{~mL}$ acetonitrile and $400 \mathrm{~mL}$ deionized water measured separately and then mixed, with an addition of $1 \mathrm{~mL}$ fresh solution of $1 \mathrm{mg} \mathrm{dithiothreitol} \mathrm{mL}^{-1}$ methanol. Standard mixtures of amino acids were used for identification and quantification of the samples. The totals of dissolved amino acids (TotAA) are given as the sum of all 20 detected and quantified amino acids. The contents are given in absolute $\left(\mu \mathrm{mol} \mathrm{g}^{-1}\right.$ dry wt.) and relative (percentage of TotAA) units.

\subsection{Carbohydrate analyses}

About $50 \mathrm{mg}$ of homogenised and dried rhizome powder were extracted with $5 \mathrm{~mL} 80 \%$ (v/v) ethanol $\left(63^{\circ} \mathrm{C}, 20 \mathrm{~min}\right)$, washed and centrifuged. The supernatant was analysed for soluble sugars. The residue was extracted with $15 \mathrm{~mL} 1.6 \mathrm{~mol} \mathrm{~L}^{-1}$ perchloric acid $\left(70^{\circ} \mathrm{C}\right.$, $120 \mathrm{~min}$ ) to determine the content of structural carbohydrate reserves. The concentration of sugars in each extract was determined by the anthrone reaction (McCready et al., 1950; Whistler et al., 1962) with glucose $\left(0-0.05 \mathrm{mg} \mathrm{L}^{-1}\right.$ final concentration) as standard.

\subsection{Statistical analyses}

The data were processed statistically using ANOVA followed by Newman-Keuls multiple range test $(P<0.05)$ to determine which means differed significantly (indicated with different capital letters in the diagrams). Spearman rank correlation coefficients $\left(r_{\mathrm{s}}\right)$ were calculated using pooled data from all reed stands and all types of shoots at a level of 
significance $P<0.01$. Data from one degree of reed damage or one type of reed shoot were also used.

\section{Results}

\subsection{Response of aquatic reeds to the extreme flood of 1999}

The flood of 1999 was extreme because (i) it was the third highest water level ever recorded at Lake Constance since 1817 , (ii) arrived very early in the season, from mid May onwards, and (iii) lasted longer than usual, until the end of June (Fig. 1). Therefore the high water level covered the first half of the growth period of $P$. australis. Many shoots, especially in the lakeside aquatic reeds were submersed, stopped their growth and died down after a few weeks. At the end of the season many stands exhibited a low shoot density and a low percentage of primary shoots. The shoots were often bent down to the water surface, and a great part of the leaf biomass was lost by grazing or by drowning and wilting (see Schmieder et al. (2002) for details).

Between summer 1998 and summer 2000 about $20 \%$ (i.e. 24 ha) of the aquatic reeds (German shoreline at Lake Constance-Untersee, only) died back (Schmieder et al., 2002). The fail area formed a fringe along the lakeside reed border, indicating that the elevation of the stand relative to the long-term mean water level of Lake Constance was an important factor. Additional to this general pattern, a high long-shore patchiness of more or less thinned stands was observed, so that other co-factors must have influenced the degree of damage. No rehabilitation or recovery was observed between 1999 and summer 2000.

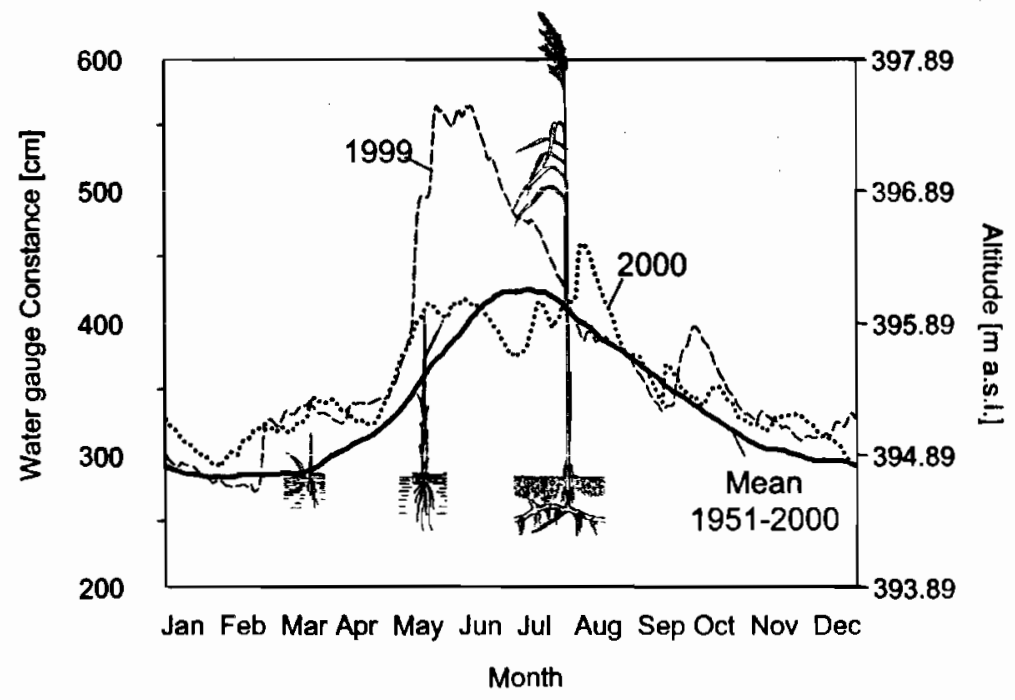

Fig. 1. Mean annual water level course of the water gauge of Constance between 1951 and 2000 in comparison to the water level courses of the years 1999 and 2000 . The phenology of the reed was added by culm symbols in the appropriate scale for illustration. 


\subsection{Stand structure, culm morphology and standing crop}

In former years, normal shoot density in Lake Constance reeds numbered 25 to $35 \mathrm{~m}^{-2}$. A year after the flood, this density level was reached only by the 'undamaged stands' (G1) whereas in the 'significantly' (G3) and 'extremely' damaged (G5) stands the density was much lower (Table 1). The shoot class composition was also significantly affected since the share of stout primary shoots (PSH) were significantly reduced in damaged stands and absent from the most damaged stands. The percentage of secondary shoots (SSH) was raised significantly with increasing damage. In former years normal values reached ca. 50-70\% for PSH but not more than about $30 \%$ for SSH (Ostendorp, unpublished data). The culm architecture within each culm class was also affected by the flood. As an example, the mean shoot height in each shoot class decreased with an increasing degree of damage, and the average culm biomass (weighted means over all shoot classes) decreased from 39.4 to 12.3 g dry wt.

\subsection{Donacia infestion and carbohydrate content of the rhizomes}

When we dug up the rhizomes in early March 2001, we saw that many rhizome internodes had been infested by Donacia larvae identified by the typical bore holes through the internode wall and from the vein-shaped necroses along the internode. The larvae and the pupae, however, had disappeared at that time. The percentage of infested rhizomes varied from 0 to $80 \%$, and reached more than $35 \%$ on average in the G3 and G5 group (Table 2). The infestation rate did not significantly depend on any sediment quality variable.

The concentration of non-structural carbohydrates was strongly affected by the degree of damage, both in the older vertical rhizomes (RVA) and in the horizontal rhizomes (RHO). The mean total carbohydrates in the RVA declined from $391 \mathrm{mg} \mathrm{g}^{-1}$ (RHO: $454 \mathrm{mg} \mathrm{g}^{-1}$ ) in the G1 group to $172(188) \mathrm{mg} \mathrm{g}^{-1}$ in the G5 group. Similarly, the concentrations of dissolved sugars and starch fell in the G5 group by half or up to one-third respectively of the concentration in the G1 group (Table 2). The carbohydrate concentrations neither depended significantly on the degree of Donacia infestion, nor on sediment quality variables.

\subsection{Content of dissolved amino acids in basal culm internodes of reed with different degrees of damage}

The total content and the composition of free amino acids (AA) in basal culm internodes revealed differences between different $P$. australis stands at Lake Constance-Untersee. The mean total content of amino acids within primary shoots (PSH) of the three undamaged reed stands G1-7, G1-8, and G1-28 ranged between 24 and $57 \mu \mathrm{mol} \mathrm{g}^{-1}$ dry wt. (Fig. 2). The significantly damaged stands G3-3, G3-21, and G3-26 contained 38-64 $\mu \mathrm{mol} \mathrm{AA} \mathrm{g}^{-1}$ dry wt. A significant higher amount of $150 \mu \mathrm{mol} \mathrm{AA} \mathrm{g}{ }^{-1}$ dry wt. was measured in basal culm internodes of the extremely damaged stand G5-23. Similar relationships were found in insect-infested shoots (ISH): $21-87 \mu \mathrm{mol} \mathrm{AA} \mathrm{g}^{-1}$ dry wt. at G1,52-72 $\mu \mathrm{mol} \mathrm{AA} \mathrm{g}^{-1}$ dry wt. at $\mathrm{G} 3$ in contrast to $193 \mu \mathrm{mol} \mathrm{AA} \mathrm{g}^{-1}$ dry wt. at the reed stand with the most damage (G5) (Fig. 3), and in secondary shoots (SSH): $15-47 \mu \mathrm{mol} \mathrm{AA} \mathrm{g}^{-1}$ dry wt. at G1 reed stands, 


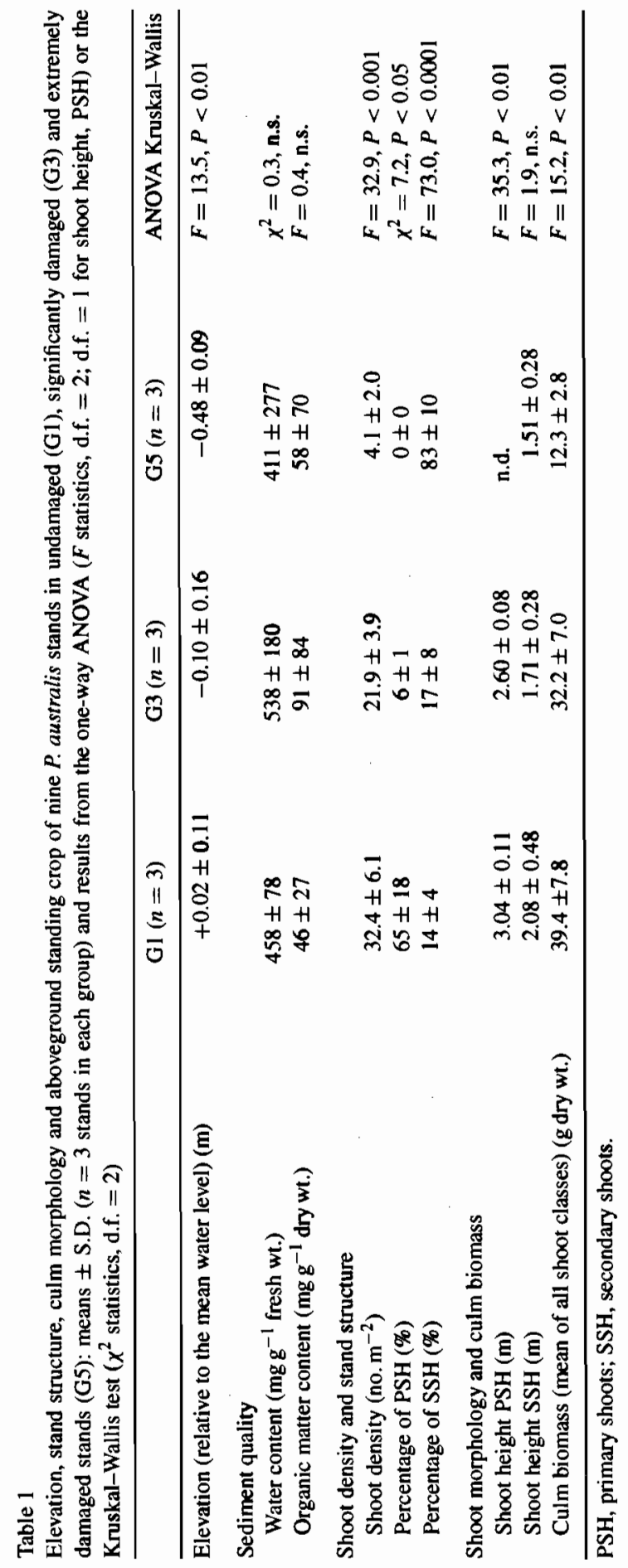


Table 2

Donacia infestion rate and carbohydrate content in the older vertical $P$. australis mizomes (RVA) and the horizontal storage rhizomes (RHO) in undamaged (G1), significantly damaged (G3) and extremely damaged stands (G5): means \pm S.D. ( $n=3$ stands in each group) and results from the one-way ANOVA $(F$ statistics, d.f. $=2)$ or the Kruskal-Wallis test $\left(\chi^{2}\right.$ statistics, d.f. $=2$ )

\begin{tabular}{|c|c|c|c|c|c|}
\hline & & $\mathrm{Gl}(n=3)$ & G3 $(n=3)$ & $\mathrm{G} 5(n=3)$ & ANOVA Kruskal-Wallis \\
\hline $\begin{array}{c}\text { Donacia damage (\% } \\
\text { of internodes) }\end{array}$ & $\begin{array}{l}\text { RVA } \\
\text { RHO }\end{array}$ & $\begin{array}{l}21 \pm 26 \\
17 \pm 29\end{array}$ & $\begin{array}{l}37 \pm 40 \\
39 \pm 35\end{array}$ & $\begin{array}{l}36 \pm 27 \\
33 \pm 58\end{array}$ & $\begin{array}{l}\chi^{2}=0.8, \text { n.s. } \\
\chi^{2}=0.7, \text { n.s. }\end{array}$ \\
\hline $\begin{array}{l}\text { Total carbohydrates } \\
\qquad\left(\mathrm{mg} \mathrm{g}^{-1} \text { dry wt.) }\right.\end{array}$ & $\begin{array}{l}\text { RVA } \\
\text { RHO }\end{array}$ & $\begin{array}{l}391 \pm 21 \\
454 \pm 22\end{array}$ & $\begin{array}{l}319 \pm 24 \\
300 \pm 134\end{array}$ & $\begin{array}{l}172 \pm 22 \\
188 \pm 100\end{array}$ & $\begin{array}{l}F=74.9, P<0.0001 \\
\chi^{2}=6.0, P=0.05\end{array}$ \\
\hline $\begin{array}{l}\text { Dissolved sugars } \\
\qquad\left(\mathrm{mgg}^{-1} \text { dry wt.) }\right.\end{array}$ & $\begin{array}{l}\text { RVA } \\
\text { RHO }\end{array}$ & $\begin{array}{l}256 \pm 5 \\
329 \pm 56\end{array}$ & $\begin{array}{l}184 \pm 49 \\
198 \pm 98\end{array}$ & $\begin{array}{l}131 \pm 19 \\
134 \pm 98\end{array}$ & $\begin{array}{l}\chi^{2}=6.5, P<0.05 \\
F=4.0, \text { n.s. }\end{array}$ \\
\hline $\begin{array}{l}\text { Starch } \\
\qquad\left(\mathrm{mg} \mathrm{g}^{-1} \text { dry wt.) }\right.\end{array}$ & $\begin{array}{l}\text { RVA } \\
\text { RHO }\end{array}$ & $\begin{array}{l}135 \pm 26 \\
124 \pm 54\end{array}$ & $\begin{array}{l}135 \pm 73 \\
102 \pm 71\end{array}$ & $\begin{array}{l}40 \pm 8 \\
54 \pm 2\end{array}$ & $\begin{array}{l}\chi^{2}=5.4, \text { n.s. } \\
\chi^{2}=6.0, P=0.05\end{array}$ \\
\hline
\end{tabular}

46-82 $\mu \mathrm{mol} \mathrm{AA} \mathrm{g}{ }^{-1}$ dry wt. at G3 stands and $126 \mu \mathrm{mol} \mathrm{AA} \mathrm{g}^{-1}$ dry wt. at G5 stands (Fig. 4). That is, there was no differentiation in total AA content (a) between types of shoots and (b) between shoots of G1 and G3 reed stands. However, there was a significant difference in AA content in extremely damaged reed stands. Reed from G5 stands had significantly

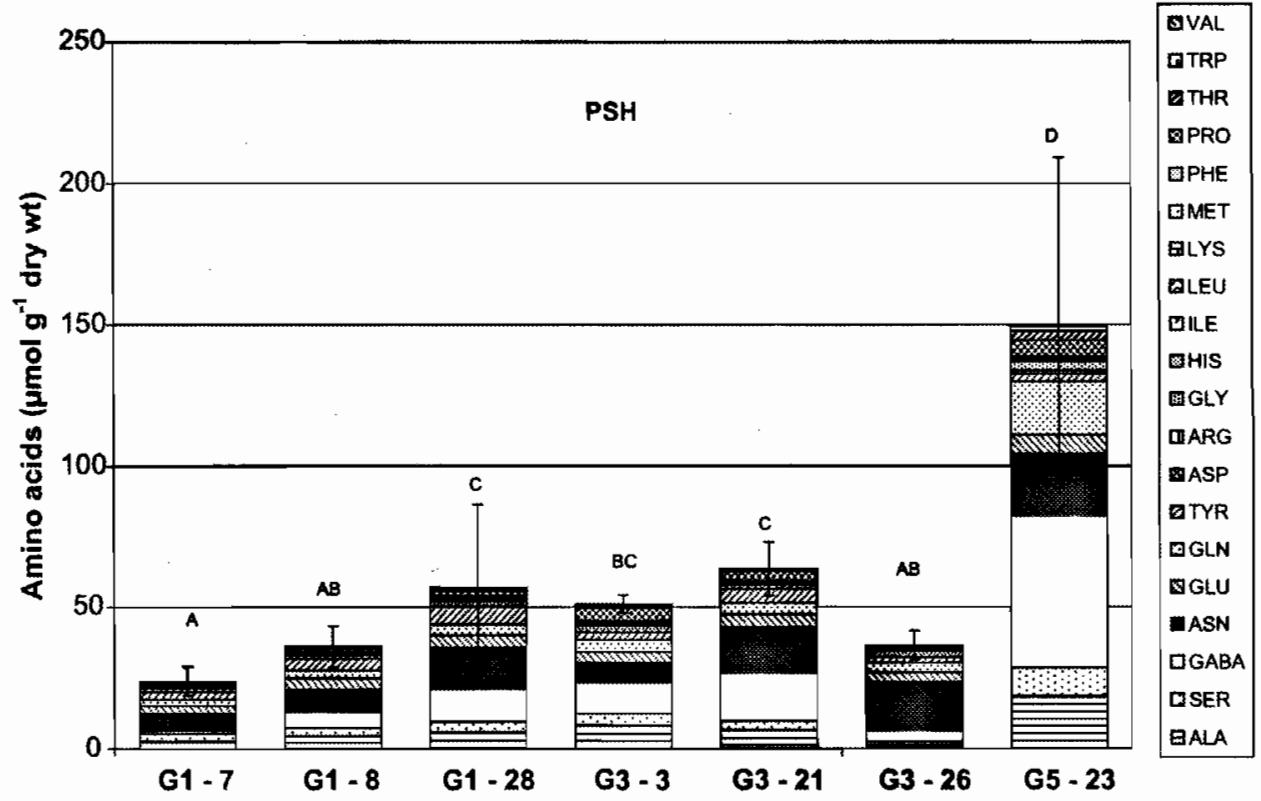

Fig. 2. Absolute content of dissolved amino acids (AA) in basal culm internodes of primary shoots (PSH) of $P$. australis stands at Lake Constance with different degrees of damage in September 2000. G1: not damaged, G3: significantly damaged, G5: extremely damaged, means $\pm 95 \% \mathrm{CL}$ of total AA content, $n=3-4$ samples, different letters indicate statistically significant differences. 


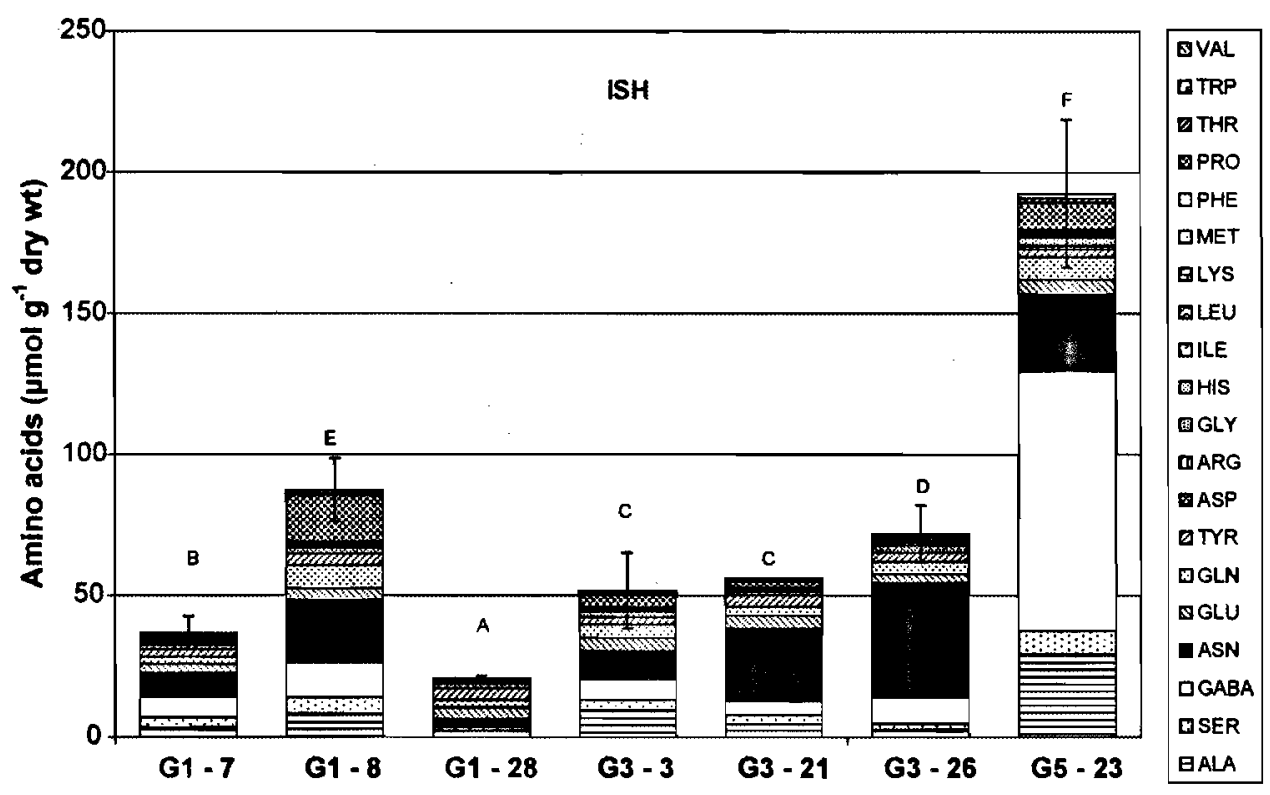

Fig. 3. Absolute content of dissolved amino acids (AA) in basal culm internodes of insect-infested shoots (ISH) of $P$. australis stands at Lake Constance with different degrees of damage in September 2000. G1: not damaged, G3: significantly damaged, G5: extremely damaged, means $\pm 95 \%$ CL of total AA content, $n=3-4$ samples, different letters indicate statistically significant differences.

higher AA contents than reed from the other stands, especially in insect-infested shoots (ISH).

\subsection{Composition of dissolved amino acids in basal culm internodes of reed with different degrees of damage}

Not only the mean content but also the fractions of individual amino acids within the pool of free AA of investigated reed stands revealed differences. These differences were especially striking for samples from extremely damaged reed stands (G5). This concerned as well the absolute content of single amino acids (Figs. 2-4) as their relative share (Figs. 5-7). There were 20 amino acids found within Phragmites shoots from Lake Constance. Among these 20 detectable AA, only asparagine, glutamine, glutamate, alanine, tyrosine, and $\gamma$-aminobutyric acid amounted to approximately $10 \%$ or more of total amino acids. Asparagine (Asn) contributed one of the largest fractions to TotAA. It amounted on average to about $25 \%$ of total AA at less damaged reed stands. Alanine (Ala) also amounted on average to more than $10 \%$ in all samples and more than $15 \%$ in ISH shoots from G5 stands. In contrast to G1 and G3 stands, the main AA of primary shoots and insect-infested shoots from extremely damaged reeds (G5) was not Asn (15\%) but $\gamma$-aminobutyric acid (Gaba). Its share was $36 \%$ in PSH and $48 \%$ in ISH, respectively. Whereas in secondary shoots from G5 stands Asn (50\%) was again the main AA (Gaba: 7\%). The relationship between 


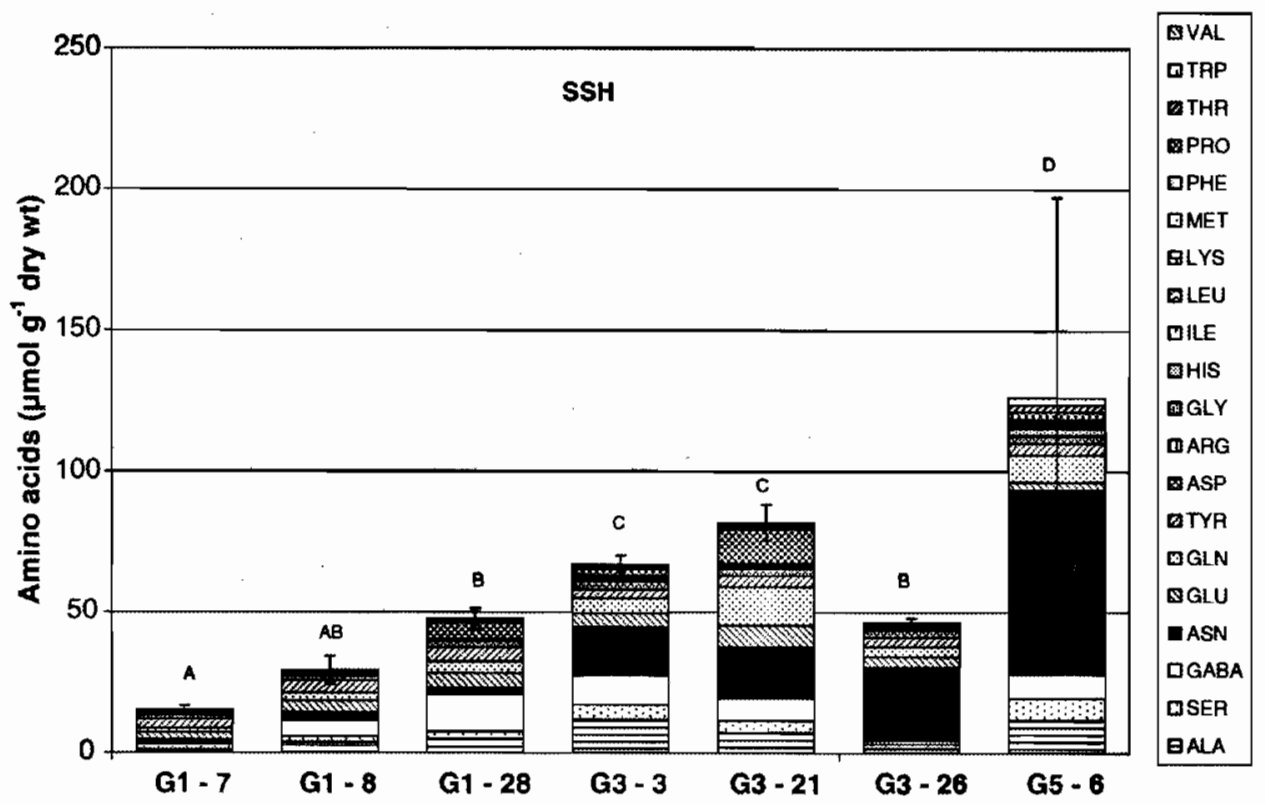

Fig. 4. Absolute content of dissolved amino acids (AA) in basal culm intemodes of secondary shoots (SSH) of P. australis stand at Lake Constance with different degrees of damage in September 2000. G1: not damaged, G3: significantly damaged, G5: extremely damaged, means $\pm 95 \%$ CL of total AA content, $n=3-4$ samples, different letters indicate statistically significant differences.

single amino acids and their total fraction was further investigated by correlation analyses of pooled data of all reed stands (G1, G3, G5) and types of culms (PSH, SSH, ISH). It was evident that the absolute content of most amino acids was positively correlated both with the sum of amino acids, and with each of the other amino acids. The comparison of the percentage of single amino acids of the total fraction revealed different specific relationships. It confirmed a significant negative correlation between Asn and Gaba (correlation coefficient, $\left.r_{\mathrm{s}}=-0,4\right)$, i.e. an increasing Asn content with decreasing Gaba. Relative Gaba content showed a positive correlation only with Ala and Pro $\left(r_{\mathrm{s}}=0.5\right)$. The share of Asn decreased with decreasing Gly $\left(r_{\mathrm{s}}=0.4\right)$ but with different increasing AA. Comparing the relative AA contents from damaged reed stands (G3 and G5) alone, the significant correlation between AA were the same, but the coefficients were obviously higher (about -0.8 and 0.8 respectively).

\subsection{Relation between amino acid concentration, culm morphology and carbohydrate content}

The total AA concentrations in the PSH and in the SSH were significantly correlated ( $r=0.943, P<0.01, n=6$ ), but no such relation between SSH and ISH, nor PSH and ISH was detected. The total AA content and the concentrations of selected amino acids (Gaba, 


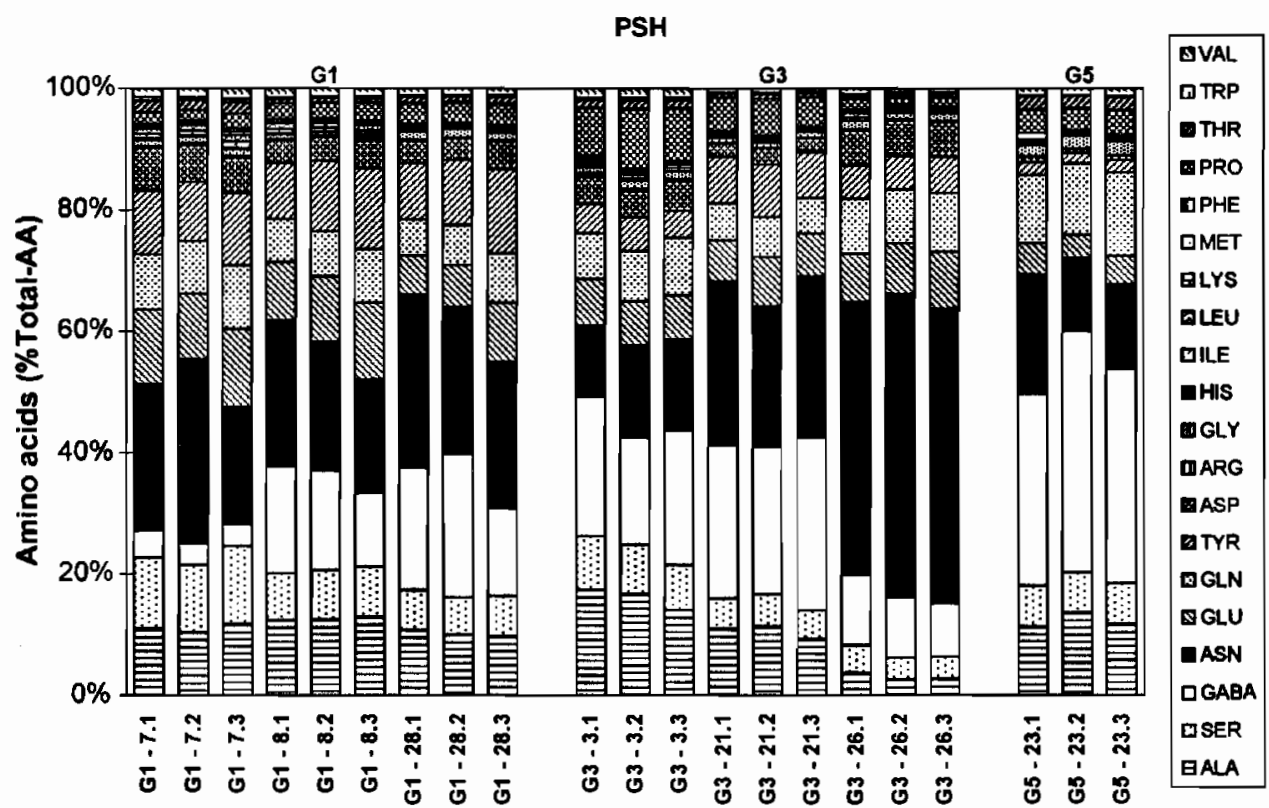

Fig. 5. Fractions of single amino acids (AA) in basal culm internodes of primary shoots (PSH) of $P$. australis stands at Lake Constance with different degrees of damage in September 2000. G1: not damaged, G3: significantly damaged, G5: extremely damaged.

Asn, Ala, Pro) were significantly correlated with some habitat and sediment variables, with the shoot density and the stand structure, and with the concentrations of carbohydrates in the older vertical rhizomes (RVA) and the horizontal rhizomes (RHO). Table 3 gives a concise overview. The relation between the relative elevation and total AA and the above mentioned AA species was always negative, i.e. the higher the elevation, the lower the concentrations of amino acids. Almost no significant correlations were detected with the water content and the content of organic matter in the sediment, and the percentage of Donacia infestion. The shoot density was negatively correlated with total AA content and with the concentrations of single AA. The percentage of secondary shoots were in all significant cases positively related with the AA content. The carbohydrate concentrations and the AA contents were, generally, negatively correlated. Many significant cases were concentrated in the total carbohydrate data of the RVA which are nearest to the basal internodes from which the samples for AA analysis were taken. Ala was the amino acid for which this negative relation was most evident.

\section{Discussion}

From recent investigations it is known that the pattern of amino acids of different $P$. australis stands differ (Kohl et al., 1998; Rolletschek et al., 1998; Koppitz et al., 1999). 
ISH

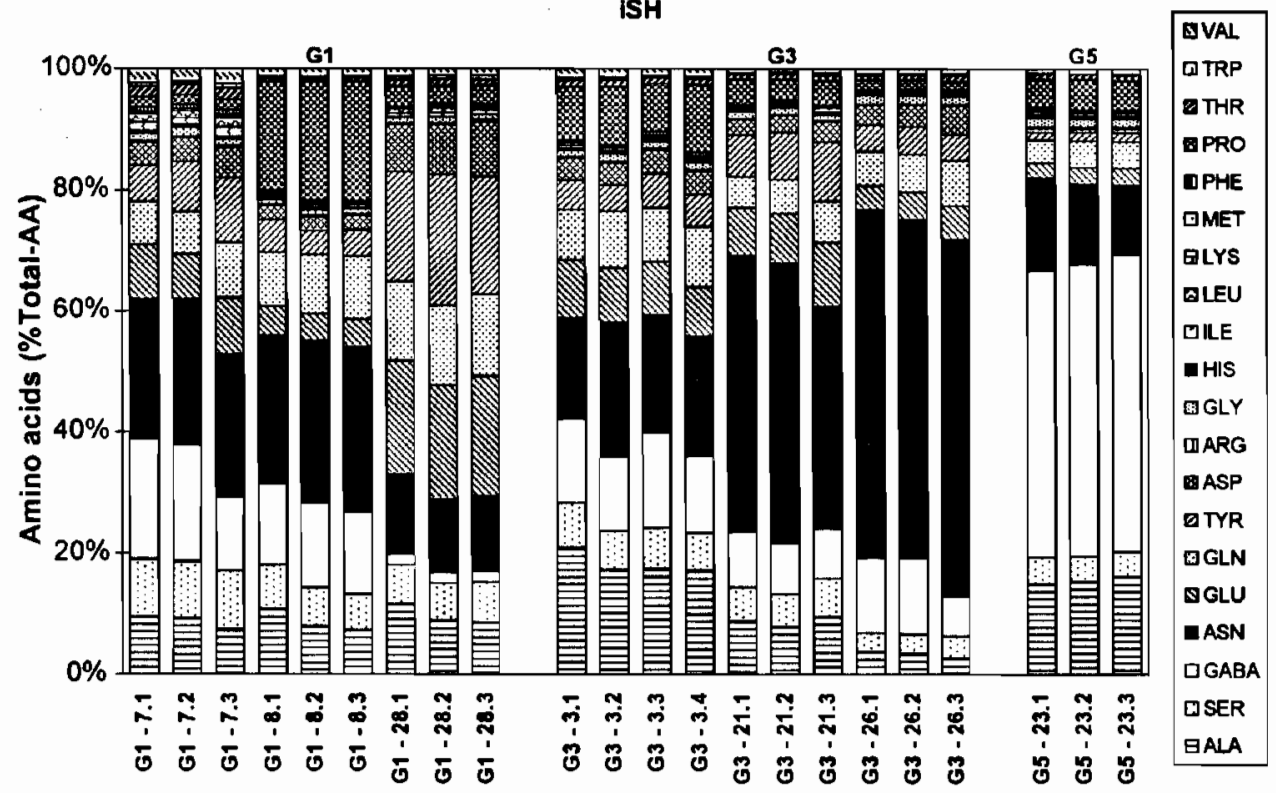

Fig. 6. Fractions of single amino acids (AA) in basal culm internodes of insect-infested shoots (ISH) of $P$. australis stands at Lake Constance with different degrees of damage in September 2000. G1: not damaged, G3: significantly damaged, G5: extremely damaged.

Our investigations build on these earlier studies on amino acid composition which have usually had to be retrospective and much less focused on specific events. Now, it has been possible to link the results immediately to a known extreme event. The results demonstrate that amino acid analysis can indicate which stands may be under stress.

The greater or lesser flood-affected reed stands at Lake Constance differ both in their absolute contents and in their composition of single amino acids. Culm bases of extremely damaged reed stands exhibited a significantly higher total content of amino acids than those from lesser affected stands. We hypothesise that this is a reaction to the initial stress to the reed due to extreme flooding during summer 1999. Similar results from other plant species support this conclusion of a stress-induced increase in the amino acid content (Sircelij et al., 1999; Zushi and Matsuzoe, 1998). Furthermore, in recent investigation it was shown that reed plants grown in flooded parts of a fen area revealed a significantly higher total amino acid content together with a lower total content of carbohydrates than those in unflooded areas (Koppitz, 2004). This finding was considered a result of the oxygen shortage in the soil.

Plants are able to synthesise all essential amino acids that are necessary for protein synthesis. Among the 20 amino acids which could be identified in Lake Constance reeds only six (asparagine, glutamine, glutamate, alanine, tyrosine, $\gamma$-aminobutyric acid) amounted to approximately $10 \%$ or more of total amino acids. We found differences in the share of individual amino acid species (i) between reed stands with varied degrees of damage (G) 


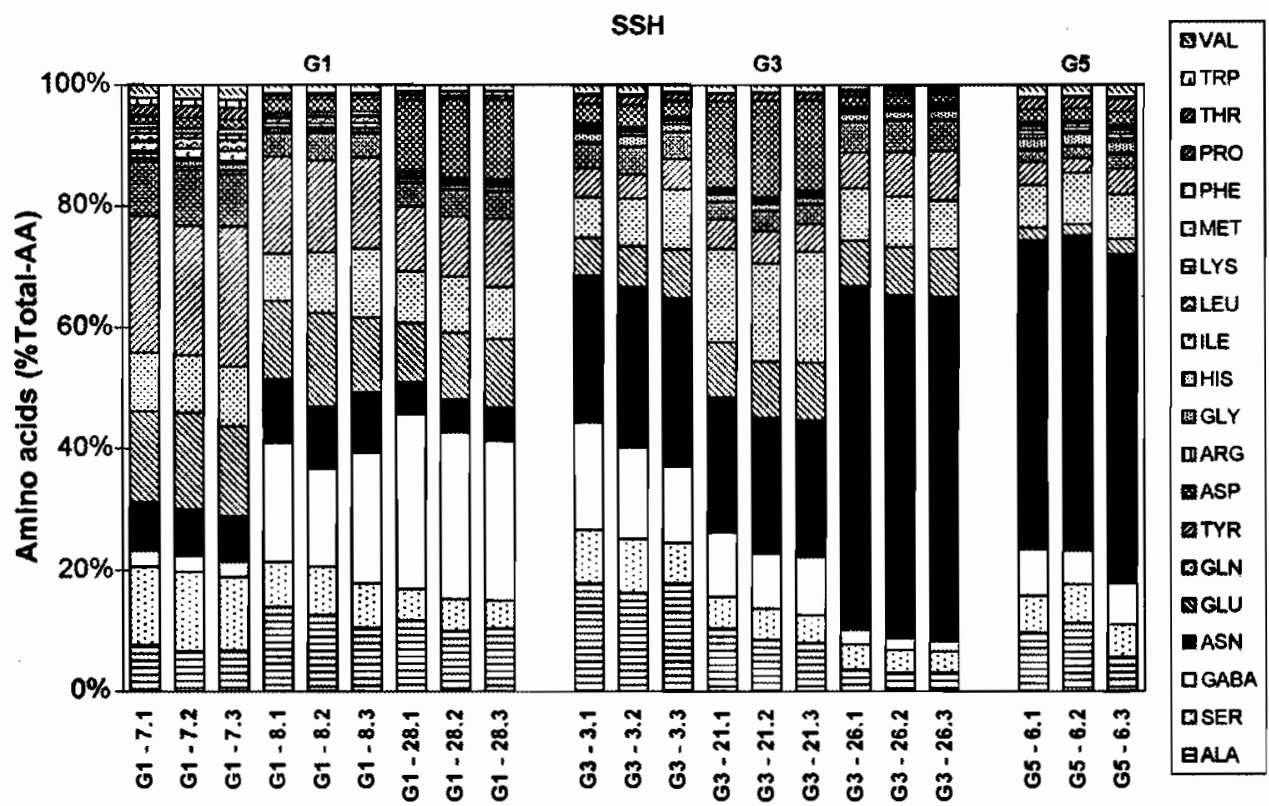

Fig. 7. Fractions of single amino acids (AA) in basal culm internodes of secondary shoots (SSH) of $P$. australis stands at Lake Constance with different degrees of damage in September 2000. G1: not damaged, G3: significantly damaged, G5: extremely damaged.

and (ii) between shoot types. Asparagine was one of the dominant amino acids, having approximately $25 \%$ of the total content of flowering or insect-infested primary shoots at undamaged and obviously damaged stands, and about $15 \%$ at extremely damaged reed stands. These findings agree well with earlier results which show that Asn is the main storage- and transport-compound of the intermediate $\mathrm{N}$ metabolism in $P$. australis (Kohl et al., 1998; Rolletschek et al., 1998; Koppitz et al., 1999).

$\boldsymbol{\gamma}$-Aminobutyric acid was a further dominant AA. The percentage of Gaba at some stands or types of shoots reached also much more than $10 \%$. Gaba accumulated especially at extremely damaged reed stands and in insect infested shoots (ISH) due to the stress of flooding. At these reed stands it amounted to about half of the total amino acids content. This is the highest Gaba content which has been reported so far in P. australis. Furthermore, the Gaba content increased along with an increase in alanine and proline.

Proline and $\gamma$-aminobutyric acid are supposed to be stress indicators. Their behaviour and accumulation in different stress conditions have already been investigated in various plant species (Dashek and Erickson, 1981; Narayan and Nair, 1990). Gaba can accumulate very rapidly in a variety of plant tissues exposed to different stress conditions, in response to hypoxia, coldness, and mechanical impact (Streeter and Thompson, 1972; Wallace et al., 1984; Bown and Shelp, 1989). There is evidence that Gaba acts as a temporary storage of nitrogen during physiologically unfavourable conditions (Sonntag and Mahn, 1998). As a result of recent investigations Kinnersley and Turano (2000) discussed the physiological 
Table 3

Correlation between total AA and selected AA and some stand variables

\begin{tabular}{|c|c|c|c|c|c|c|c|}
\hline Amino acid & $\begin{array}{l}\text { Relative } \\
\text { elevation }\end{array}$ & $\begin{array}{l}\text { Total shoot } \\
\text { density } \\
\left(\mathrm{m}^{-2}\right)\end{array}$ & $\begin{array}{l}\text { Secondary } \\
\text { shoots }(\%)\end{array}$ & $\begin{array}{l}\text { Total } \\
\text { nonstructural } \\
\text { carbohydrates } \\
\text { (RVA) }\end{array}$ & $\begin{array}{l}\text { Soluble } \\
\text { sugars } \\
\text { (RVA) }\end{array}$ & $\begin{array}{l}\text { Total } \\
\text { nonstructural } \\
\text { carbohydrates } \\
\text { (RHO) }\end{array}$ & $\begin{array}{l}\text { Soluble } \\
\text { sugars } \\
\text { (RHO) }\end{array}$ \\
\hline \multicolumn{8}{|l|}{ Total AA } \\
\hline PSH & - & - & $+t+$ & -- & & - & -- \\
\hline SSH & & & ++ & -- & - & & - \\
\hline ISH & & -- & +++ & --- & & & \\
\hline \multicolumn{8}{|l|}{ Gaba } \\
\hline $\begin{array}{l}\text { PSH } \\
\text { SSH }\end{array}$ & - & & +++ & -- & & & -- \\
\hline ISH & -- & -- & & -- & & & \\
\hline \multicolumn{8}{|l|}{ Asn } \\
\hline PSH & - & & ++ & & & & \\
\hline $\begin{array}{l}\text { SSH } \\
\text { ISH }\end{array}$ & -- & -- & +++ & --- & & & \\
\hline \multicolumn{8}{|l|}{$\mathrm{Ala}$} \\
\hline PSH & & & ++ & - & - & - & -- \\
\hline SSH & & & & & --- & -- & --- \\
\hline ISH & - & -- & ++ & -- & & -- & - \\
\hline \multicolumn{8}{|l|}{ Pro } \\
\hline $\begin{array}{l}\text { PSH } \\
\text { SSH } \\
\text { ISH }\end{array}$ & & & & & --- & -- & --- \\
\hline
\end{tabular}

Relative elevation, elevation of the reed stand relative to the mean water level; RVA, older vertical rhizomes; RHO, horizontal storage rhizomes; symbols:,,,,,++++++------ , significantly positive or negative rank correlation (Spearman), $P<0.05, P<0.01, P<0.001$.

role of Gaba in stress mitigation of plants. Gaba accumulation was thus explained by two mechanisms: (1) stress factors such as cold, heat, salt, and mild or transient environmental factors such as touch, wind, rain, etc. will rapidly increase cellular levels of $\mathrm{Ca}^{2+}$. This stimulates the calmodulin-dependent glutamate decarboxylase activity and thereby the Gaba synthesis. (2) Stress causing metabolic and/or mechanical disruptions may lead to cytosolic acidification, and induce an acidic $\mathrm{pH}$-dependent activation of glutamate decarboxylase and therefore an enhanced Gaba synthesis rate. A strong decline in cytosolic $\mathrm{pH}$ can occur under oxygen deprivation, being the primary stress factor in flooded soils, and this stress induces the greatest accumulation of Gaba.

$P$. australis exhibits an outstanding capacity to vent its underground tissue by pressurised gas-throughflow, to supply oxygen from the atmosphere to their roots and rhizomes, which grow in the flooded, anoxic sediment, and to remove microbial metabolic end products $\left(\mathrm{CH}_{4}, \mathrm{CO}_{2}\right)$ from the rhizosphere (Armstrong and Armstrong, 1990). A reduced convective gas-flow rate affects the oxygen supply and may induce hypoxia in the below-ground organs (Armstrong and Armstrong, 1990; Brix et al., 1992). Convective gas flows may be impaired by a change of the water level, by the mechanical damage of culms, insect and fungal attack 
or by callus formation (Armstrong et al., 1996). This hypoxia stress may induce an increase of Gaba within severely damaged reed stands, as shown in our study. We hypothesise that the anaerobic metabolism which leads to an exhaustion of carbohydrate reserves in extremely damaged reeds, leads at the same time to an accumulation of Gaba. Additional stress factors such as mechanical damage to the surviving shoots or infestation by gall-forming insects (ISH) may intensify this process. Secondary shoots emerge from subapical buds on the upper vertical rhizome nodes when the apical dominance of the original primary shoot is weakened. This being due to mechanical damage or destruction of the upper part of the primary shoot. They are a compensatory response of the reed stand to biomass loss. This may be the background to asparagine-generally the main transport compound of the $\mathrm{N}$ metabolism of reed-being the dominant amino acid in secondary shoots.

The reduced oxygen supply to parts of the plants below ground causes a metabolic shift towards anaerobic processes (Brändle and Crawford, 1987) together with a change in central metabolic pools in the cell (Kohl et al., 1978; Armstrong et al., 1994) which in turn affects the amino acid metabolism (Kohl et al., 1998; Rolletschek et al., 1998). The limited oxygen supply leads to a decrease in respiratory phosphorylation and to the accelerated consumption of carbohydrate reserves from the rhizomes to stabilise the adenylate energy charge (AEC) (Cizkova-Koncalova et al., 1992; Armstrong and Armstrong, 2001). Therefore, reed die-back sites often exhibit lower total non-structural carbohydrate (TNC) concentrations than unaffected sites (Dinka and Szeglet, 1999). This was demonstrated also in our study, where the TNC content was highest in the 'undamaged' reeds group (G1) and decreased to an average between 172 and $188 \mathrm{mg} \mathrm{g}^{-1}$ in the 'extremely damaged' reed groups. We propose that a concentration of approximately $100-150 \mathrm{mg} \mathrm{g}^{-1}$ could be the minimum requirement for sustained survival of a reed stand. However, these figures are higher than annual minimum values stated in other literature (e.g. Dinka and Szeglet, 1999, Cizkova et al., 2001).

The limited oxygen supply and decrease in respiratory phosphorylation also leads to an accumulation of glycolytic intermediates, such as pyruvate. Such products are removed from the metabolism by transamination of pyruvate and 3-phosphoglycerate to alanine and serine. This leads to a weakening of the end product inhibition of the glycolysis so that the glycolytic metabolism is accelerated (Good and Muench, 1993). The advantage of this pathway is that the anaerobic ATP production is combined with the avoidance of cytosolic acidification (Roberts et al., 1992; Crawford et al., 1994) and the assimilation of nitrogen (Kohl and Henning, 1987). The accumulation of alanine and serine in addition to Gaba in response to anaerobic metabolism has been described in various plant species, including P. australis (Kohl and Henning, 1987; Haldemann and Brändle, 1988; Good and Muench, 1993; Rolletschek et al., 1998). In this study, an increase of the amino acids Ala, Ser and Gaba was identified in extremely damaged reed stands within Lake Constance, indicating oxygen deprivation, whilst the percentage of Asn decreased. In primary shoots from these stands the content of Ala + Ser + Gaba was $55 \%$ of total-AA and in insect-infested shoots it amounted to $67 \%$ (in comparison to about $30 \%$ in lesser or undamaged reed stands), caused by a strong increase of Gaba and a slight increase of Ala.

As a consequence of the flood damage to lakeside reed from May and June 1999 we found a consistent pattern of a die-back syndrome, characterised by a strong decrease in total culm density, an increase in percentage of secondary shoots and a decline in mean culm biomass. 
The die-back syndrome is further characterised by a reduction of TNC, starch and soluble sugars in the vertical and in the horizontal rhizomes. In correlation with the above results an increase in total AA content and changes in the amino acid composition in the basal culm internodes, namely an increase in the contents of Gaba and Ala was also noted. The amino acid pattern of $P$. australis is assumed to be an indicator of the aerobic/anaerobic status of the metabolism in the plant tissue. Changes in the composition of amino acids are shown to be useful as indicators of stress, such as oxygen deprivation. In this investigation in primary shoots from extremely damaged reed stands, there was found (1) a significant increase in total content of amino acids and (2) a significant increase in the share of $\gamma$-aminobutyric acid and a slight increase of alanine. This hints to a strong impairment of the extreme flooding having caused a mechanical damage of culms and a reduced oxygen supply on the metabolism and thus possibly on the vitality of reed stands. To summarize, the results demonstrate that amino acid analysis can indicate which stands may be under stress.

\section{Acknowledgements}

This study was financed by the BWPLUS-Program of the country of Baden-Württemberg (BWC 20011).

\section{References}

Armstrong, J., Armstrong, W., 1990. Light-enhanced convective throughflow increases oxygenation in rhizomes and rhizosphere of Phragmites australis (Cav.). Trin. ex Steud. New Phytol. 114, 121-128.

Armstrong, J., Armstrong, W., 2001. An overview of the effects of phytotoxins on Phragmites australis in relation to die-back. Aquat. Bot. $69(2-4), 251-268$.

Armstrong, W., Brändle, R., Jackson, M.B., 1994. Mechanisms of flood tolerance in plants. Acta Bot. Neerl. 43, 307-358.

Armstrong, J., Armstrong, W., Armstrong, I.B., Pittaway, G.R., 1996. Senescence, and phytotoxin, insect, fungal and mechanical damage: factors reducing convective gas-flows in Phragmites australis. Aquat. Bot. 54, 211226.

Bidlingmeyer, B.A., Cohen, S.A., Tarvin, T.L., 1984. Rapid analysis of amino acids using pre-column derivatization. J. Chromatogr. 336, 93-104.

Bown, A.W., Shelp, B.J., 1989. The metabolism and physiological roles of 4-aminobutyric acid. Life Sci. Adv. 8, 21-25.

Brändle, R., Crawford, R.M.M., 1987. Rhizome anoxia tolerance and habitat specialisation in wetland plants. In: Crawford, R.M.M. (Ed.), Plant Life in Aquatic and Amphibious Habitats. Blackwell, Oxford, UK, pp. 397-410.

Brix, H., 1999. The European research project on reed die-back and progression (EUREED). Limnologica 29, 5-10.

Brix, H., Sorrell, B.K., Orr, P.T., 1992. Internal pressurization and convective gas flow in some emergent freshwater macrophytes. Limnol. Oceanogr. 37, 1420-1433.

Cizkova, H., Istvanovics, V., Bauer, V., Balazs, L., 2001. Low levels of reserve carbohydrates in reed (Phragmires australis) stands of Kis-Balaton, Hungary. Aquat. Bot. $69(2-4), 209-216$.

Cizkova-Koncalova, H., Kvet, J., Thompson, K., 1992. Carbon starvation a key to reed decline in eutrophic lakes. Aquat. Bot. 43 (2), 105-113.

Cohen, S.A., Strydom, D.J., 1988. Amino acid analysis using phenylisothiocyanate derivates. Anal. Biochem. 174, 1-16.

Crawford, L.A., Brown, A.W., Breitkreuz, K.E., Guinel, F.C., 1994. The synthesis of gamma-aminobutyric acid in response to treatments reducing cytosolic pH. Plant Physiol. 104, 865-871. 
Dashek, W.V., Erickson, S.S., 1981. Isolation, assay, biosynthesis, metabolism, uptake and translocation, and function of proline in plant cells and tissues. Bot. Rev. 47, 349-385.

Dinka, M., Szeglet, P., 1999. Carbohydrate and nutrient content in rhizomes of Phragmites australis from different habitats of Lake Ferto/Neusiedlersee. Limnologica 29 (1), 47-59.

Good, A.G., Muench, D.G., 1993. Long-term anaerobic metabolism in root-tissue-metabolic products of pyruvate metabolism. Plant Physiol. 101, 1163-1168.

Hagen, S.R., Augustin, J., Grings, E., Tassinari, P., 1993. Precolumn phenylisothiocyanate derivatization and liquid chromatography of free amino acids in biological samples. Food Chem. 46, 319-323.

Haldemann, C., Brändle, R., 1988. Amino acid composition in rhizomes of wetland species in their natural habitat and under anoxia. Flora 180, 407-411.

Kinnersley, A.M., Turano, F.J., 2000. Gamma aminobutyric acid (GABA) and plant responses to stress. Crit. Rev. Plant Sci. 19 (6), 479-509.

Kohl, J.-G., Henning, M., 1987. Amino acid content and pattern as an indicator of the hyperfertilization of regressive stands of common reed Phragmites australis (Cav.) Trin: ex Steudel. Arch. Hydrobiol. Beih. Ergebnisse der Limnologie 27, 203-210.

Kohl, J.-G., Baierova, J., Radke, G., Ramshorn, K., 1978. Regulative interaction between anaerobic catabolism and nitrogen assimilation as related to oxygen deficiency in maize roots. In: Hook, D.D., Crawford, R.M.M. (Eds.), Plant Life in Anaerobic Environments. Science Publishers, Ann arbor, MI, pp. 473-496.

Kohl, J.-G., Woitke, P., Kühl, H., Dewender, M., König, G., 1998. Seasonal changes in dissolved amino acids sugars in basal culm internodes as physiological indicators of the $\mathrm{C} / \mathrm{N}$-balance of Phragmites australis at littoral sites of different trophic status. Aquat. Bot. 60, 221-240.

Koppitz, H., 2004. Effects of flooding on the amino acid and carbohydrate patterns of Phragmites australis. Limnologica 34, 37-47.

Koppitz, H., Kühl, H., Geißler, K., Kohl, J.-G., 1999. Vergleich der Entwicklung verschiedener auf einem wiedervernäßten Niedermoor etablierter Schilfklone (Phragmites australis). 11. C/N-Haushalt und Druckventilation der Rhizome. Arch. für Nat.-Lands 38, 167-191.

Luft, G., van den Eertwegh, G., 1991. Long-term Changes in Water Level of Lake Constance and Possible Causes, vol. 206. 1AHS Publications, Wallingford, UK, pp. 31-44.

McCready, R.M., Guggolz, J., Silviera, V., Owess, S., 1950. Determination of starch and amylose in vegetables. Anal. Chem. 22, 1156-1158.

Narayan, V.S., Nair, P.M., 1990. Metabolism, enzymology and possible roles of 4-aminobutyrate in higher plants. Physiol. Plant. 80, 507-514.

Ostendorp, W., 1989. Die-back of reeds in Europe-a critical review of literature. Aquat. Bot. 35, 5-26.

Ostendorp, W., 1990. Die Ursachen des Röhrichtrückgangs am Bodensee-Untersee. Carolinea 48, 85-102.

Ostendorp, W., Dienst, M., Schmieder, K., 2003. Disturbance and rehabilitation of lakeside Phragmites reeds following an extreme flood in Lake Constance (Germany). Hydrobiologia 506-509, 687-695.

Ostendorp, W., Blum, H., 1998. Hemmenhofener Methoden: sedimentologische und paläolimnologische Methoden in der Siedlungsarchåologie. Siedlungsarchäologie im Alpenvorland, vol. V, pp. 243-313.

Roberts, J.K.M., Hooks, M.A., Miaullis, A.P., Edwards, S., Webster, C., 1992. Contribution of malate and amino-acid-metabolism to cytoplasmic $\mathrm{pH}$ regulation in hypoxic maize root-tips studied using nuclear-magnetic-resonance spectroscopy. Plant Physiol. 98 (2), 480-487.

Rolletschek, H., Bumiller, A., Henze, R., Kohl, J.-G., 1998. Implications of missing efflux sites on convective ventilation and amino acid metabolism in Phragmites australis. New Phytol. 140, 211-217.

Schmieder, K., Dienst, M., Ostendorp, W., 2002. Auswirkungen des Extremhochwassers 1999 auf die Flächendynamik und Bestandsstruktur der Uferröhrichte des Bodensees. Limnologica 32, 131-146.

Sircelij, H., Batic, F., Stampar, F., 1999. Effects of drought stress on pigment, ascorbic acid and free amino acid content in leaves of two apple tree cultivars. Phyton 39 (3), 97-100.

Sonntag, H.-W., Mahn, E.G., 1998. Untersuchungen zum EinfluB unterschiedlich hohen Angebots und verschiedener Nutzungintensität auf den Gehalt einzelner Aminosäuren ausgewählter Segetalarten unter Agrarökosystembedingungen. Angew Bot. 72, 99-106.

Streeter, J.G., Thompson, J.F., 1972. In vivo and in vitro studies on 4-aminobutyric acid metabolism with the radish plant (Raphanus sativus L.). Plant Physiol. 49, 579-584.

Van der Putten, W.H., 1997. Die back of Phragmites australis in European wetlands: an overview of the European research programme on reed die-back and progression (1993-1994). Aquat. Bot. 59, 263-275. 
Wallace, W., Secor, J., Schrader, L.E., 1984. Rapid accumulation of 4-aminobutyric acid in soybean leaves in response to an abrupt transfer to lower temperature, darkness, or mechanical manipulation. Plant Physiol. 75, $170-175$.

Whistler, R.L., Wolfrom, M.L., Miller, J.N.B., Shafizadeh, F. (Eds.), 1962. Methods in Carbohydrate Chemistry, vol. 1. Academic Press, New York, pp. 390, 490-491.

Zushi, K., Matsuzoe, N., 1998. Effect of soil water deficit on vitamin C, sugar, organic acid, amino acid and carotene contents of large-fruited tomatoes. J. Jpn. Soc. Horticultural Sci. 67 (6), 927-933. 